\title{
The Elements of Ethnography "Speaking" in Fist Fight Movies (2017)
}

\author{
Ni Ketut Sukiani ${ }^{1}$, I Gusti Ngurah Agung Wira Hadijaya ${ }^{2}$ \\ Faculty of Letters, Universitas Warmadewa Denpasar-Bali, Indonesia ${ }^{1,2}$ \\ \{sukiani@gmail.com ${ }^{1}$, igusti.ngurah@gmail.com ${ }^{2}$ \}
}

\begin{abstract}
This study discusses the elements of ethnography which is found in Fist Fight Movie using Hymes's theory. The data sources collected by watching the movie. In analyzing the element of ethnography "speaking" which found in the movie. The main theory used in data analisis is taken theory of Dell Hymes. The researcher uses descriptive qualitative research in designing this study, due to it explain what exist and may assist with revealing new realities and importance. The concepts about the element ethnography is also taken from the supporting theories. The result of the study, it is found that there are eight components of ethnography, they are setting, members, ends, act, key, instrument, standards, and genre, where each conversation gives a different analysis. In this movie the researcher found 32 scenes that fit and can be analyzed with the theory of Dell Hymes. However, the researcher elected 10 scenes of the movie to be described in this study.
\end{abstract}

Keywords: Communication; Ethnography; Speaking

\section{Introduction}

Utterance is regularly utilized in activity movement and correspondence with others in each circumstance. Expression is significant in correspondence to introduce what the speaker's expectation to the listeners and it is the physical creation of semantic conduct. Finding the importance of articulation is one of numerous approaches to get the message from the expressions and in every day action individuals have a discourse network in their current circumstance.Despite the fact that communication through signing may not be joined by any vocalization, it shares all different highlights of verbal correspondence with speech. In marking, a scope of visual practices notwithstanding hand developments (which would be viewed as nonverbal in speech) work on the verbal measurement. These incorporate some outward expression, which may even capacity at a syntactic level in the code [1]. In addition, ethnography is a field of study which is concerned essentially with the portrayal and investigation of culture, and linguistics is a field concerned, in addition to other things, with the depiction and analysis of language codes, [1]. Regardless of long-standing consciousness of the interrelationship of language and culture, the engaging and expository results of ethnographers and linguists traditionally neglected to manage this interrelationship. Indeed, even anthropological linguists and linguistic anthropologists until the 1960s regularly concentrated on the way that the employments of language and discourse in various social orders have 
examples of their own which are deserving of ethnographic depiction, compatible to - and meeting with - designs in social association and other social culture areas. [2] There have been 'travellers tales' for quite a long time, returning even to artifact, which consider a type of ethnographic examination in that they suspected to speak to some part of social reality based on close associate with and perception of it, although regularly they reflected the social and political prejudices of their own general public.

Ethnography is the investigation of social associations, conduct, and recognitions that happen inside gatherings, groups, associations, and networks. Its foundations can be followed back to anthropological investigations of little, rustic (and regularly distant) social orders that were attempted in the mid 1900s and applied to an assortment of metropolitan settings in their investigations of public activity. An ethnographic methodology gives an investigation of language as one aspect of a mind boggling example of activities and convictions that offer importance to individuals lives. Reliable to this presumption, our example investigation doesn't just zero in on inquiries inside various kinds of discussion, yet additionally objectives, settings, members, and different acts that establish the speech functions.

The ethnography of correspondence investigates how and why language is utilized, and how its utilization changes in various societies. The ethnography of correspondence is a way to deal with talk that reviews open skill. It does as such by finding and examining the examples (structure) and elements of imparting that sort out the utilization of language (in speech circumstances, functions, and acts) in the direct of public activity. Moreover, diverse discourse acts, for example, narrating, tattling, kidding, addressing, talking with, sonnet, fantasy, story axiom, question, revile, petition, speech, business, structure, letter, article, and so on [3]. Besides that Fist Fight movie is an interesting and valuable movie to be analyzed. The language use in this film has some extraordinary culture and assortments. At the point when diverse rank in the public arena has impacted in public activity, the assortments of language are appeared in this film. So it will be a test for research to analyze this. Other than that, this film contains generally excellent virtue to their spectators. The communication is investigated through the components of ethnography of correspondence named talking hypothesis. By finding of every components the researcher can locate the significance of every components and surmising the exchange. But in this research, the researcher analyzed Fist Fight movie (2017). The researched was ethnography of communication with theory by Dell Hymes named Speaking theory to analyze between linguistics and anthropology in this movie, Fist Fight movie (2017). The writer also conducts this research not only using S.P.E.A.K.I.N.G theory by Hymes but also compared the theory of considerations on ethnography of communication, which is speech and cultural rules.

The following section would be mentioned about latest relevant research. Firstly, a research done [4] ethnographic movies are spellbinding in goal, educated by a hypothesis of culture which now and again has been converted into a methods for arranging the pictures, tend not to uncover technique (either inside the film or somewhere else on paper), and utilize a specific verbally expressed/composed anthropological dictionary however don't utilize a particular visual anthropological vocabulary. Secondly, a research carried out [5] that ethnography is a profoundly valuable technique for tending to a scope of exploration inquiries inside the wellbeing callings. Specifically, it can create rich and point by point records of clinicians' expert and interprofessional connections, their collaborations with patients, and their ways to deal with conveying care, just as top to bottom records of patients' consideration encounters. Understanding the establishments of ethnography and its key components will help us when they run over reports that utilization this methodology. 
Then lastly, a research conducted [6], the analyst finds that the utilization of language is affected by subject varieties and circumstances. From 28 information investigated by the analyst, some information has finished the components of ethnography of correspondence. In any case, there are 7 information which has no finished the components of ethnography of correspondence. The most missing components are standard and closures. Based on the description above, the formulation of problem are as directs what are the components of ethnography "speaking" in Fist Fight Movies? And how many scenes found in Fist Fight movie?.

\section{Method}

In analyzing the data, the researcher utilizes descriptive qualitative research. It explained what exist and may assist with revealing new realities and importance. The motivation behind graphic subjective examination is to watch and depict parts of circumstance that happens in discussion. It will reach inference about the matter of the consequence of the analysis.

At that point the researcher records the information as discussion or discourse dependent on the theme varieties. In investigating the information, the scientist utilizes theory of SPEAKING by Dell Hymes to clarify the components of ethnography of expressing in Fist Fight motion movies (2017). Subsequent to investigating the information, the researcher depicts about certain viewpoints and results that discovered during the cycle of analysis. The description of the investigation is finished up dependent on the analysis of the information by utilizing the components of ethnography of correspondence by Dell Hymes hypothesis.

\section{Results and Discussion}

Discussion can be broke down to Setting, Participant, Ends, Act, Key, Instrumental, Norms, and Genre. The components of ethnography are available detail in the accompanying:

\section{a) Scene 1}

This is the beginning scene of the movie. This conversation happens when Campbell and the student when to the school by their vehicle and looking for the parking lot in the parking area in the morning before the school begins.

Campbell : Whoa! Hey! Buddy, excuse me. I'm sorry, you're parking in my spot..

Student : Senior prank day.

Campbell : Yeah, but it's not a prank. You're just parking it in an assigned. That's fine. You're good. You're good. I'll find a new spot.

Based on this dialogue above, there are two participants, the setting place is in the parking area, and the time is in the morning settings. The end of the conversation is to tell that parking lot is not for the students. The act of this conversation is informal but Campbell said politely while drive his car but the student ignores what Campbell says. The key is serious, the instrumental is oral and the norm is loudness. The genre is storytelling because Campbell tells the student that the parking lot is not for the students.

\section{b) Scene 2}


This dialogue happens when the students rocking Maher's car with him inside the car. And Campbell talking to Maher and passed. This scene happens after Campbell got the parking lot.

Maher : Fucking rent-a-cop. Guys! I need you to stop rocking the cart. Fuck you!

I'm gonna write your names down.

Campbell : Well, that's not good.

There are two participants in the dialogue above, they are Maher and Campbell, the setting time is in the morning. The setting place is in the parking area. The End of this conversation is to tell the students to stop rocking the cart. The Acts of this conversation Informal because Maher using harsh language and the student rocking the cart. The Key of this conversation is Serous and Loudness, the Instrumental is oral, the norm is gaze return and the genre is storytelling and curse.

\section{c) Scene 3}

This dialogue above happens when Strickland found school's 1971 championship bat in the trash can, he asks the students in the student hall about it, when Strickland saw them in the student hall, he saw his student are watching porn video. The setting time is in the morning, before the bells ringing.

Strickland : Hey!

Student : Oh, fuck!

Strickland : You hold it right there. Now, outside my class, I found our school's 1971 championship bat in the trash can. I'm wondering who put it in there and why.

Student $\quad$ : We thought it'd be funny to throw out the bat and put the computer in with porn.

Strickland : Put it back. Now! Now get y'all Rush Hour asses to class. Everybody!

In this dialogue above there are two participants, they are student and Strickland. The setting place of this conversation is in the student hall. The Ends of this conversation is Strickland told the student to return the display and told all of the students to go back to the class. The Acts is Informal and the students are afraid of Strickland and they restore the display. The Key is Serious, the Instrumental is oral, the norm is gaze return and loudness, and the genre is storytelling.

\section{d) Scene 4} Holly.

This dialogue happens when Campbell looking for his mug and then he shares his story to

Campbell : Where... Where is my mug? Why are people always taking my mug? You know, I know we're a rough school and everything, and we don't usually have control over the students, but this is the worst I've ever seen the pranks.

Holly : Really? I think it's hilarious. I'm thinking about taking a shit in the pool.

Campbell : I want... I want to think, that you're joking. But for some reason, I feel like you're not.

Holly : I was just picturing everybody's faces.

Campbell : Yeah. I'm just saying it's not a good day for this, you know? My wife was due three days ago. And I'm up all night thinking about what I'm gonna say to the superintendent at 2:00. You know, I don't have anything planned. 
In this dialogue above there are two participants, they are Campbell and Holly. The setting place of this conversation is in the teacher's room, the time is in the morning settings. before the class begins. The Ends of this conversation is Campbell tells about his complaints at the school and his home. The Acts is Informal because they are talking while making a drink, the Key is Casual but a little bit harsh, the Instrumental is oral, and the genre is storytelling and curse.

\section{e) Scene 5}

This dialogue happens Crawford, Campbell, and Holly gathering together in the teacher's room and talking about their students.

Crawford : I know what I'm gonna say at my meeting. I'm gonna be like, "Fuck you for trying to make us re-interview for our jobs again!" I put my blood, sweat, and tears into my coaching.

Campbell : Right.

Crawford : Not my fault we always in last place.

Campbell : Yeah, what... What is your record?

Crawford : These kids are un-coachable!

Campbell : It's very tough. It's very tough.

Crawford : Losing here is a tradition.

Campbell : It shouldn't be.

Holly : Yeah, it's a terrible tradition.

Campbell : Right?

Crawford : I'm trying my best, not to get one of these kids' moms pregnant. I'm trying.

Campbell : You're not gonna say that, are you?

Crawford : Hell no, Campbell. Be polite as shit. I went out and bought new jeans for this motherfucker. And I hate long pants.

Holly : Yeah, you got an exotic build.

Based on dialogue above, there are three participants, they are Crawford, Campbell, and Holly. The setting place is in the teacher's room. The time is in the morning settings before the class begin. The Acts of this conversation is informal, because Crawford vent about the students who uncoachable. The acts is informal because Crawford is too emotional and harsh speaking, but does not take excessive action. The key of this conversation is serous, the instrumental oral, the norms is gaze return, Crawford describes his annoyance and the genre is storytelling and curse.

\section{f) Scene 6}

This dialogue happens when Irv come to the teacher's room and said that he got fired. He takes some stuff in there to himself.

Irv $\quad$ : Fuck this! Twenty-two years and then, "See you later!" Those assholes should have taken my class, so they can manage a fucking budget! I'm taking this. Taking this.

Crawford : See? We're expendable.

Campbell : Ahh..

Holly : They fired Irv.

Irv : This school's gonna fuck me? I'm gonna fuck it! 
Based on dialogue above there are four participants. They are Irv, Crawford, Campbell, and Holly. The setting place of this conversation is in the teacher's room, the setting time is in the morning. The end of this conversation is Irv wants to tell his complaints. The act is Irv using harsh language with abusive behavior with a very upset face. The key is serious but very loud voice, the instrumental is oral, the norm is loudness and the genre is curse and storytelling.

\section{g) Scene 7}

This dialogue happens when Strickland come to the teacher's room and found a new coffee machine in the pantry. He confused how to use the new coffee machine, so he asks Campbell to help him make a cup of coffee.

Strickland : What the fuck is this? Don't have money for books, but got money for this newfangled...

Crawford : He gonna fuck that coffee machine up.

Strickland : Is this a practical joke? Huh? You know I don't play that shit. How the fuck you work this bullshit?

Strickland : You. Campbell.

Campbell : Me?

Strickland : You the only one drinking coffee, right?

Campbell : Uh, yeah. No, I mean, I got a light roast cappuccino.

Strickland : Well, get your light Roast ass over here and help me fix a cup.

Campbell : Right. Yeah, sure. Yeah.

Based on dialogue above there are three participants, they are Strickland, Campbell and Crawford. The setting place is in the teacher's room, the setting time is in the morning before the class begin. The Ends is Strickland calls Campbell to help him make a cup of coffee, the acts is slightly rough because Strickland pointed at Campbell and told him to come closer. The key of this conversation is serious, the instrumental is oral, the norm is loudness, and genre is storytelling.

\section{h) Scene 8}

This dialogue happens when Strickland who cannot use a new coffee machine. Campbell tell him how to use coffee machine, but Strickland still cannot use it. In the end Campbell make a cup of coffee to Strickland.

Campbell : Yeah, so it's a new machine.

Strickland : No shit.

Campbell : It's state of the art, though. All you gotta do is put in your order, and it does the rest.

Strickland : Coffee

Campbell : You know, I'll just, I'll do it for you, and I think that's just gonna be the easiest. Right, so you got your drink selections down here. And flavors, you got hazelnut...

Strickland : I just want regular coffee.

Campbell : Shoot. Uh... That doesn't seem to be an option. Um...How about an Americano? That's basically the same thing.

Strickland : Whatever.

Campbell : So I just pick "Americano", right? And then you can go medium, light, dark. 
You look like... Or not look like, you would want... I'll go with medium. And then you hit "brew." And it's done. Thank God. And one Americano. For you. All right. Cheers.

Strickland : Tastes like shit. Fucking waste of money. Shit don't even voice activate.

Campbell : That was awkward.

The ends of this conversation is Campbell who helping Strickland to use a new coffee machine. The setting place of this conversation is teacher's room and the time is in the morning settings. The respondent is Campbell and Strickland. The end of this conversation is Campbell teaches Strickland how to use a coffee machine. The act is Campbell tells Strickland while showing a direct operation. The key is serious, the instrumental is oral, the norms gaze return and the genre is storytelling.

\section{i) Scene 9}

This dialogue happens when Campbell teaching in the front of the class, and talk about how words become an important and has a meaning. But the students are laughing on him and they are pranking him.

Campbell : : "It takes courage to grow up and to become who you really are." Right?

E.E. Cummings wrote that. And, guys, you're growing up. You're moving on. For many of you, this is gonna be the last English class you're ever gonna take. So, um, i want you to remember something. Words are always going to matter. Right? What? Uh-oh! Uh... Something's funnier than it should be, right? I'm missing the joke here. Is it me? "Mr. Dick Suck's English class!" Look, I'm down for the senior pranks, I really am, but, frankly, I think this one's a little homophobic, right? I mean, how does everybody think this makes Blake feel?

Blake : What's that supposed to mean?

Campbell : Oh, uh... I'm sorry. It doesn't mean anything.

Blake : No, no. It means something. Words matter, remember?

Campbell : Right. Yeah, no. I... I just meant because you're politically conscious and you're sensitive.

Blake : I'm not sensitive. I'm gay. And I wrote it and I drew the cat.

Campbell : And now there's a cat. What is... What is this? Now I'm Mr. Cat? Oh, I see. I'm Mr. Pussy because I'm a good guy. I'm a weakling, right? All right, guys, come on. I'm down for the pranks, but frankly we're getting. And "Mr. Dick Suck's English class" again!

Based on dialogue above, there are two participants in this conversation, they are Campbell, and Blake. The end is taught the students, but the students mocked his teacher. The act of teaching normally, but Campbell a little bit surprised by the actions of students. The key is serious, the instrumental is oral, the norms is slightly against the teacher and the genre is proverb and jokes.

\section{j) Scene 10}

This dialogue happens when Campbell still teaching in the front of the class, Holly calls him to go outside and she tells Campbell that their teacher friends got fired on that day.

Campbell : Hey!

Holly : Hey, how's it going? 


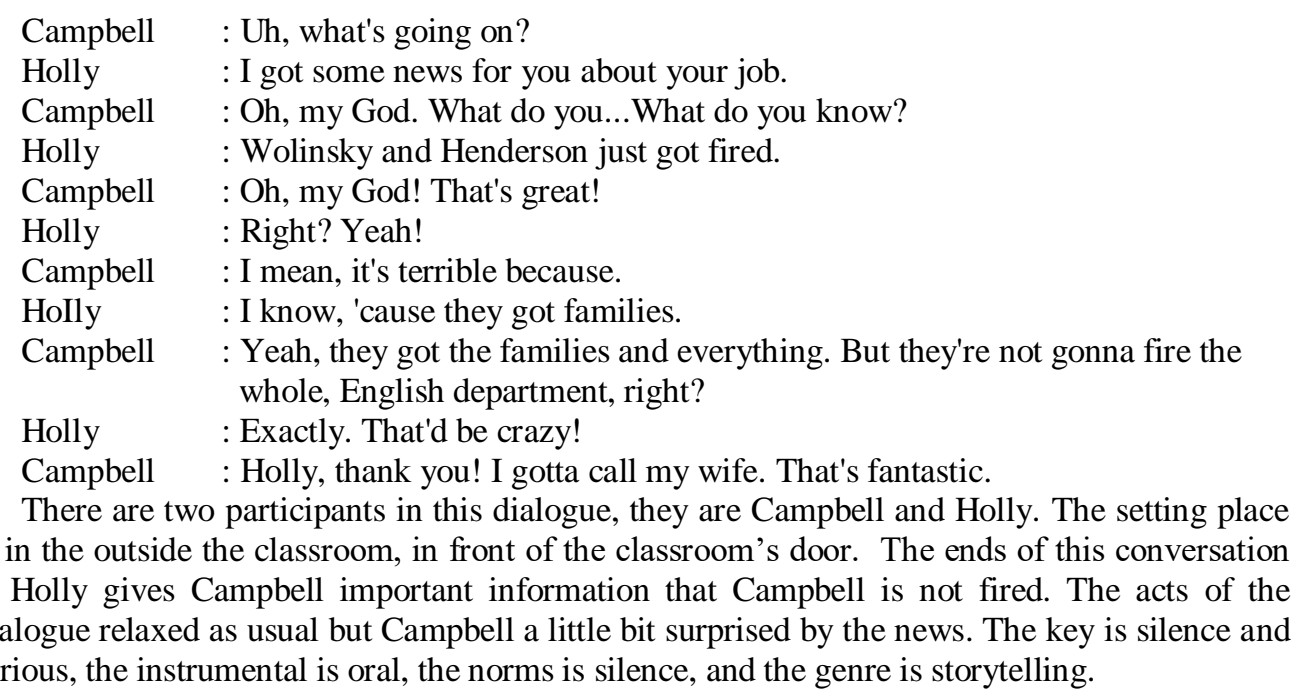

\section{Conclusion}

In viewing on the data analysis of element ethnography of speaking in Fist Fight Movies (2017), there are some points, which can be considered as the conclusion of this study. According to Dell Hymes theory, the writer got the element that corresponds to Dell Hymes theory, there are 8 elements of ethnography speaking is setting, participants, ends, act, key, instrument, norms, and genre, where each conversation gives a different analysis. In this movie, the writer found 24 conversations that fit and can analyze with the theory of Dell Hymes. However, researcher elected 10 scenes of the movie to be described in this study.

\section{References}

[1] M. S. Troike, The Ethnography of Communication: An Introduction, 3 Edition. Malden: Blackwell Publishing, 2003.

[2] J. . Brewer, Ethnography. Buckingham: Open University Press, 2000.

[3] M. Matei, "The Ethnography of Communication. Buletin of the Trasilvania University of Brasov. Series IV," Philology and Cultural studies, vol. 2, no. 51, 2009.

[4] J. Ruby, "Is an Ethnographic Film a Filmic Ethnography?," Studies in the Anthropology of Visual Communications, vol. 2, no. 2, pp. 104-111, 1975.

[5] S. Reeves, A. Kuper, and B. D. Hodges, "Qualitative research: Qualitative research methodologies: Ethnography,” Bmj, vol. 337, no. 7668, pp. 512-514, 2008.

[6] R. Pujianto, "Ethnography of Communication Analysis in Jane Eyre Movie (2011)," no. 2011, pp. 1-20, 2016. 